Supporting Information for:

\title{
Origin of the Anomalous Temperature Dependence of the Photochromic Reaction of Cu-Doped ZnS
}

\section{Nanocrystals}

Yusuke Sanada, Daisuke Yoshioka, and Yoichi Kobayashi*

Department of Applied Chemistry, College of Life Sciences, Ritsumeikan University, 1-1-1 Nojihigashi, Kusatsu, Shiga 525-8577, Japan.

E-mail: ykobayas@fc.ritsumei.ac.jp

\section{CONTENTS}

1. Syntheses and Preparations of Samples $\quad$ S2

2. Experimental Setups $\quad$ S3

3. Powder XRD Patterns $\quad$ S4

4. TEM Images $\quad$ S5

$\begin{array}{ll}\text { 5. FTIR Spectra } & \text { S7 }\end{array}$

6. Steady-State Absorption and Emission Spectra $\quad S 8$

7. Time Evolutions of the Differential Diffuse Reflectance Spectra of MPA1 S9

8. Time Evolutions of the Differential Absorption Spectra of a $\mathbf{3 H}$-Napthopyran Polymer Film

9. FTIR Spectra of MPA1 and MPA2 before and after Drying S13

10. Time Evolutions of the Differential Diffuse Reflectance Spectra of MPA2 $\quad$ S14

$\begin{array}{lr}\text { 11. Arrhenius Plots } & \text { S17 }\end{array}$

12. TG-DTA Curves $\quad$ S18

13. Calculation of the Amounts of Water Molecules Adsorbed on the Surface of NCs S20

$\begin{array}{ll}\text { 14. References } & \text { S21 }\end{array}$ 


\section{Syntheses and Preparations of Samples}

\section{Materials}

Zinc acetate dihydrate $\left(\mathrm{Zn}\left(\mathrm{CH}_{3} \mathrm{COO}\right)_{2} \cdot 2 \mathrm{H}_{2} \mathrm{O}, 98 \%\right.$, Wako), bis(2,4-pentanedionato)copper(II) $\left(\mathrm{Cu}\left(\mathrm{C}_{5} \mathrm{H}_{7} \mathrm{O}_{2}\right)_{2}\right.$, $>97 \%$, TCI), sodium sulfide nonahydrate $\left(\mathrm{Na}_{2} \mathrm{~S} \cdot 9 \mathrm{H}_{2} \mathrm{O},>98 \%\right.$,Wako), 3-mercaptopropionicacid (MPA, $>98 \%$, TCI), sodium hydroxide (97\%, Wako), 3,3-diphenyl-3H-naphtho[2,1-b]pyran (3H-naphthopyran, TCI), poly(methylmethacrylate) (PMMA, Wako Co. Ltd, PTK2051), Zinc Chloride ( $\mathrm{ZnCl}_{2}, 98 \%$, Wako), Copper(II) Chloride $\left(\mathrm{CuCl}_{2}\right.$, Wako), tri- $n$-octylphosphine oxide (TOPO, $>95 \%$, TCI), hexadecylamine $(>95 \%$, TCI), and oleylamine ( $>95 \%$, Wako) were used without further purification.

\section{MPA capped Cu-doped ZnS Nanocrystals (MPA1 and MPA2).}

Syntheses of the $\mathrm{Cu}$-doped $\mathrm{ZnS}$ nanocrystals (NCs, MPA1 and MPA2) were carried out by following a previous study. ${ }^{1}$ The amounts of the reagents used in the syntheses are shown in Table S1. Specifically, $\mathrm{Zn}\left(\mathrm{CH}_{3} \mathrm{COO}\right)_{2} \cdot 2 \mathrm{H}_{2} \mathrm{O}$ and $\mathrm{Cu}\left(\mathrm{C}_{5} \mathrm{H}_{7} \mathrm{O}_{2}\right)_{2}$ were dissolved in deionized water. Then 3-mercaptopropionic acid (MPA) was added to the solution, and $\mathrm{pH}$ of the mixed solution was adjusted to 10.3 with a $2 \mathrm{M}$ aqueous solution of $\mathrm{NaOH}$. After $\mathrm{N}_{2}$ bubbling for $30 \mathrm{~min}$, a $0.46 \mathrm{M}$ aqueous solution of the $\mathrm{Na}_{2} \mathrm{~S}$ was quickly injected into the solution under vigorous stirring at room temperature. The mixed solution was kept for $15 \mathrm{~min}$ under magnetic stirring, then heated to $100^{\circ} \mathrm{C}$, and the temperature was kept for $24 \mathrm{~h}$ to form the NCs. The obtained $\mathrm{Cu}$-doped $\mathrm{ZnS}$ NCs were precipitated by ethanol (solution:ethanol $=4: 1)$, centrifuged $\left(12,000 \mathrm{rpm}\right.$ for $5 \mathrm{~min}$ ), and then the precipitate was dried in vacuum at $40^{\circ} \mathrm{C}$.

Table S1. The amounts of the reagents used in the syntheses.

\begin{tabular}{cccccc}
\hline & $\begin{array}{c}\mathrm{Zn}\left(\mathrm{CH}_{3} \mathrm{COO}\right)_{2} \cdot 2 \mathrm{H}_{2} \mathrm{O} \\
/ \mathrm{mmol}\end{array}$ & $\begin{array}{c}\mathrm{Cu}\left(\mathrm{C}_{5} \mathrm{H}_{7} \mathrm{O}_{2}\right)_{2} \\
/ \mathrm{mmol}\end{array}$ & $\mathrm{MPA} / \mathrm{mmol}$ & $\mathrm{Na}_{2} \mathrm{~S} / \mathrm{mmol}$ & $\begin{array}{c}\text { Total volumes of } \\
\text { water } / \mathrm{ml}\end{array}$ \\
\hline MPA1 & 5 & 0.05 & 23.0 & 2.3 & 255 \\
MPA2 & 12.5 & 0.115 & 57.5 & 5.7 & 407 \\
\hline
\end{tabular}

\section{Cu doped ZnS NCs capped with long alkyl amines (OLA).}

$\mathrm{Cu}$-doped $\mathrm{ZnS}$ NCs capped with long alkyl amines were synthesized with slightly modified procedures of the previous studies. ${ }^{2,3}$ Specifically, $0.042 \mathrm{~mol}$ of hexadecylamine, $0.010 \mathrm{~mol}$ of tri- $n$-octylphosphine oxide (TOPO) and $3.98 \mathrm{mmol}$ of $\mathrm{ZnCl}_{2}$ were loaded in a three-neck flask and heated to $70^{\circ} \mathrm{C}$. The mixture was degassed for 20 min under vacuum. Then the reaction flask was heated to $170^{\circ} \mathrm{C}$ and stirred for $1 \mathrm{~h}$ under $\mathrm{N}_{2}$ atmosphere. $6 \mathrm{mmol}$ of sulfur dissolved in $4 \mathrm{~mL}$ of oleylamine prepared at room temperature was injected into the zinc-oleylamine solution at $170^{\circ} \mathrm{C}$. This mixture was heated to $300^{\circ} \mathrm{C}$ and aged for $5 \mathrm{~min}$ at the same temperature. The temperature was dropped to $250^{\circ} \mathrm{C}$ and the solution of the $\mathrm{Cu}$ ion, which was prepared by dissolving $0.045 \mathrm{mmol}^{\circ} \mathrm{CuCl}_{2}$ into oleylamine at room temperature, was added to this mixture. The mixture solution was annealed for $20 \mathrm{~min}$ at $250^{\circ} \mathrm{C}$. Then, ZnS NCs were separated by adding excess ethanol and centrifugation. The precipitate was redissolved in a small amount of chloroform. ZnS NCs were precipitated using methanol and methanol was removed by decantation after the centrifugation. This procedure was repeated two times. Finally, ZnS NCs were precipitated using acetone. The white precipitation was dried for one day under vacuum and the pale-yellow powder was obtained. 


\section{Preparation of a polymethyl methacrylate film of $3 \mathrm{H}$-naphthopyran.}

$1.1 \mathrm{mg}$ of 3,3-diphenyl-3H-naphtho[2,1-b]pyran (3H-naphthopyran) and $50.2 \mathrm{mg}$ of polymethyl methacrylate (PMMA) (Wako Co. Ltd, PTK2051) were dissolved in $0.7 \mathrm{~mL}$ chloroform. Three drops of the prepared solution were casted on a cover slide and dried on a hot plate at $40^{\circ} \mathrm{C}$ for $30 \mathrm{~min}$. Then, the cover slide was further dried under vacuum for $2 \mathrm{~h}$ at $40^{\circ} \mathrm{C}$.

\section{Experimental Setups}

\section{Setups for Material Characterization and Steady-State Optical Measurements.}

Wide-angle X-ray diffraction (XRD) patterns were recorded by a X-ray diffractometer (Rigaku Ultima IV). Smallangle region XRD measurements were carried out on a Rigaku SmartLab X-ray diffractometer with Cu-Ka parallel beam method and $\theta-2 \theta$ scan mode. The size and morphologies of NCs were analyzed by a transmission electron microscope (JEOL JEM-2100plus) operating at $200 \mathrm{kV}$. Organic functional groups on the surface of NCs were analyzed by a Fourier transform infrared (FTIR) spectrometer (HORIBA FT-720 combined with an attenuated total reflection setup, resolution: $2 \mathrm{~cm}^{-1}$ ) and JASCO FT/IR-6100. Thermogravimetry (TG) and differential thermal analysis (DTA) were analyzed by a SHIMADZU DTG-60AH.

\section{Time Evolution of the Differential Diffuse Reflectance Measurements.}

A schematic and a picture of the setup are shown in Figure S1. A CW 365-nm UV light (LC-L1 V3, HAMAMATSU) was used as the excitation source. A multichannel spectrometer (OCEAN FX, Ocean Optics) was used as a detector. The accumulation time was set to $10 \mathrm{~s}$, and the time zero was set to the time just after stopping UV light irradiation. For temperature-dependent measurements, the temperature of the powder was controlled by water chiller (NCB-2500, EYELA), and the sample temperature was measured by a type K thermocouple. To control the relative humidity, the setup was covered with an acryl box and dried $\mathrm{N}_{2}$ gas was continuously flowed. The relative humidity was monitored by a hygrometer (TR-72wf, T\&D). The obtained data were analyzed by Matlab.
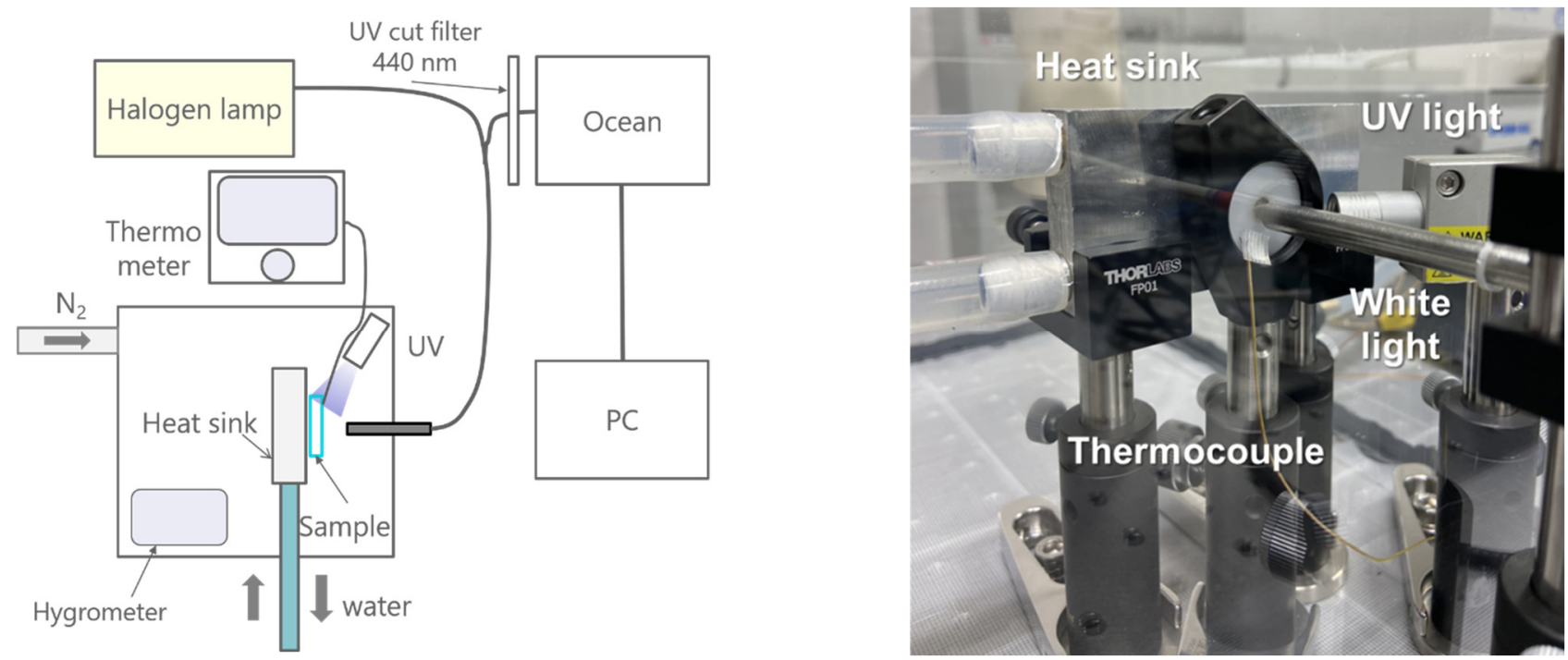

Figure S1. Schematic and a picture of the setup for time-resolved differential diffuse reflectance spectra. 


\section{Powder XRD Patterns}

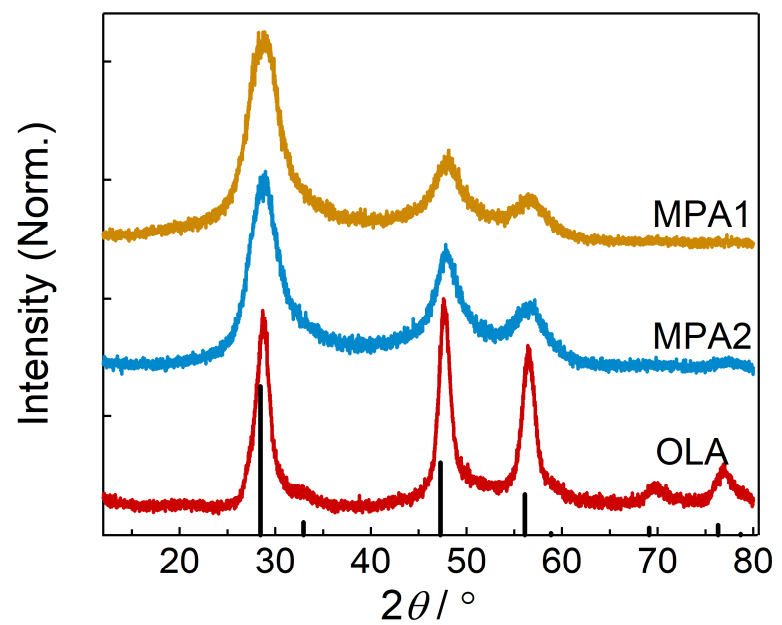

Figure S2. Wide-angle X-ray diffraction patterns of Cu-doped ZnS NCs (MPA1, MPA2, OLA). Vertical lines indicate the cubic zincblende structure of ZnS (JCPDS 01-071-5976). 


\section{TEM Images}

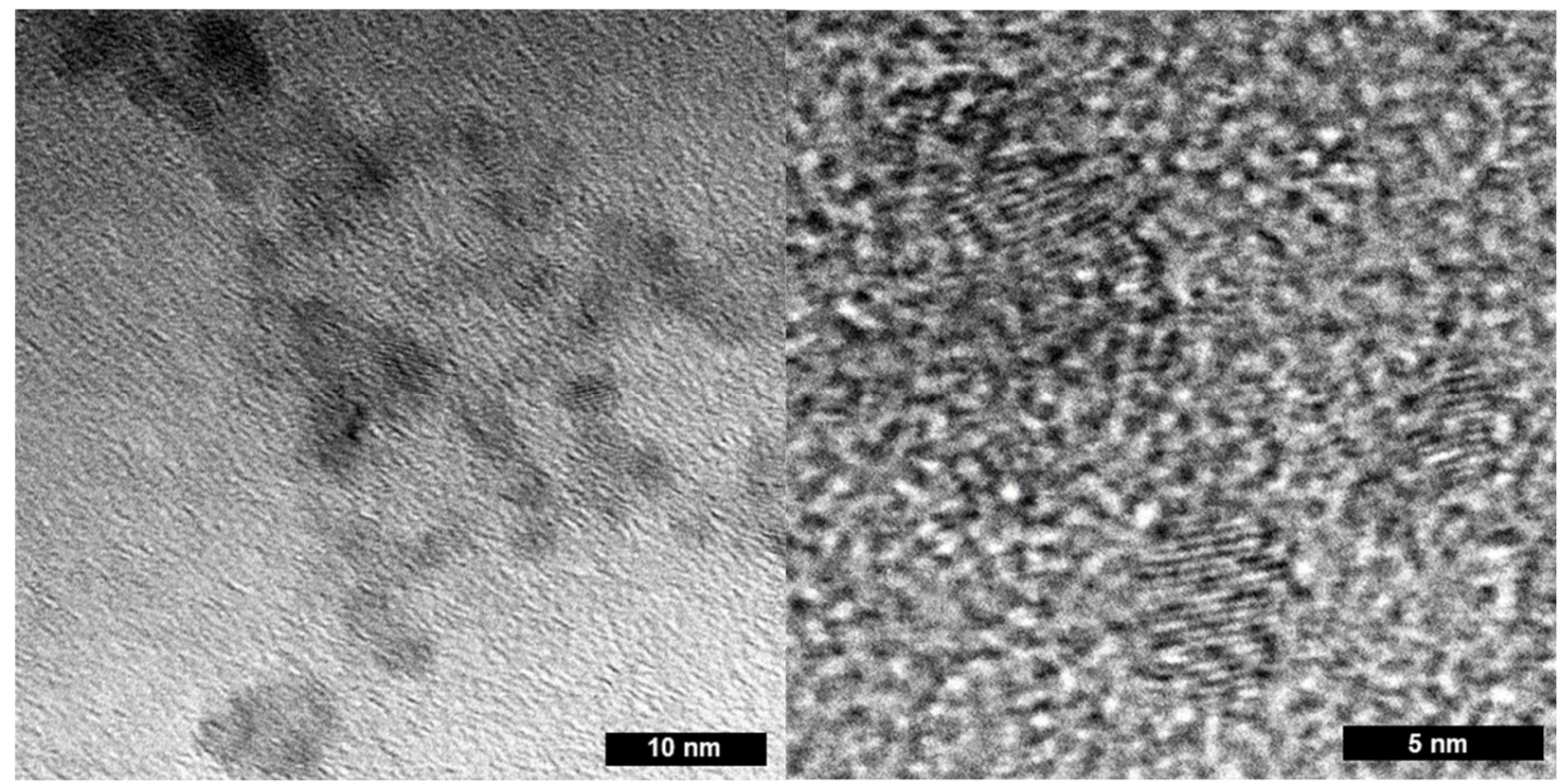

Figure S3. TEM images of MPA1.

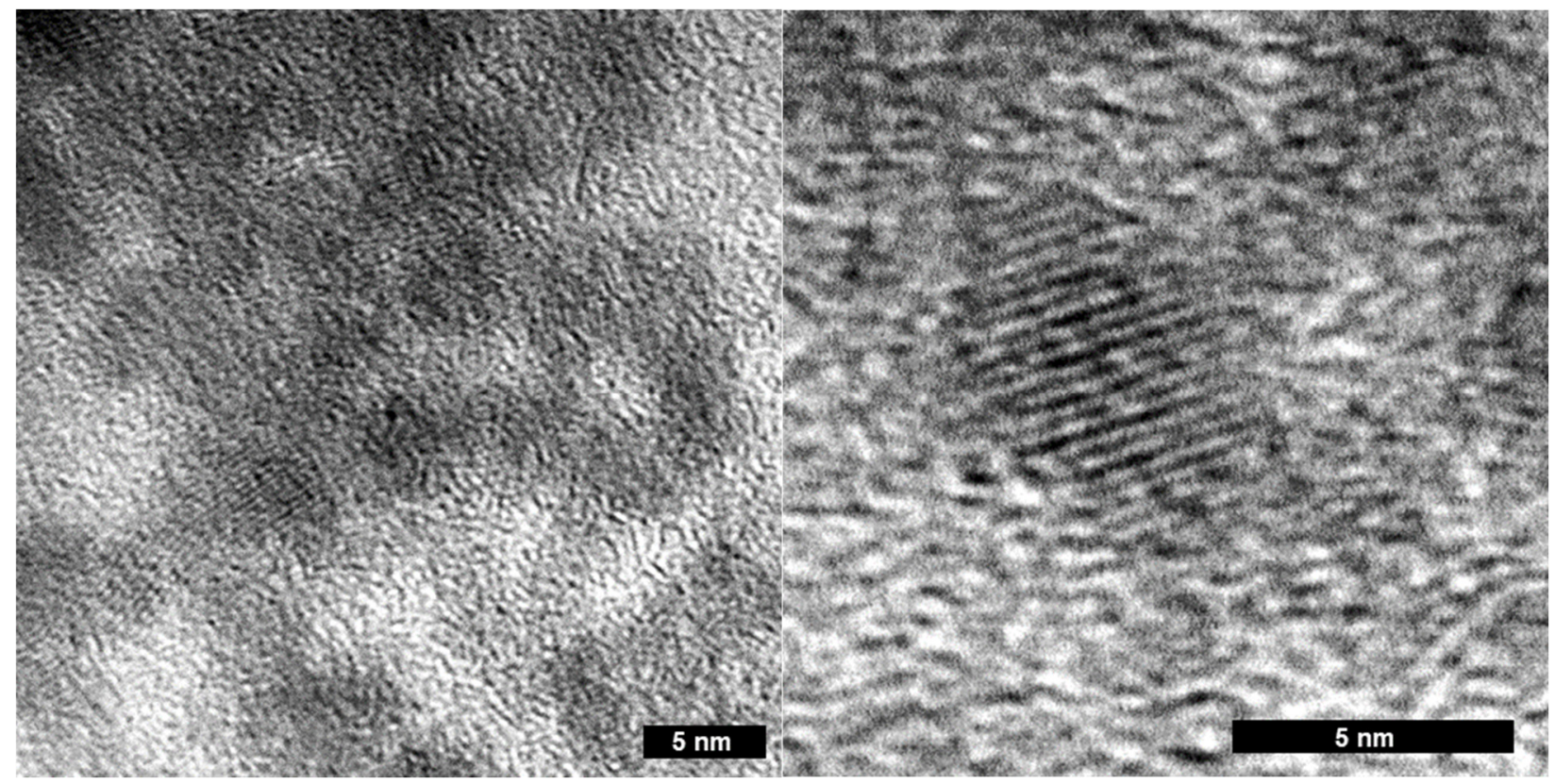

Figure S4. TEM images of MPA2. 


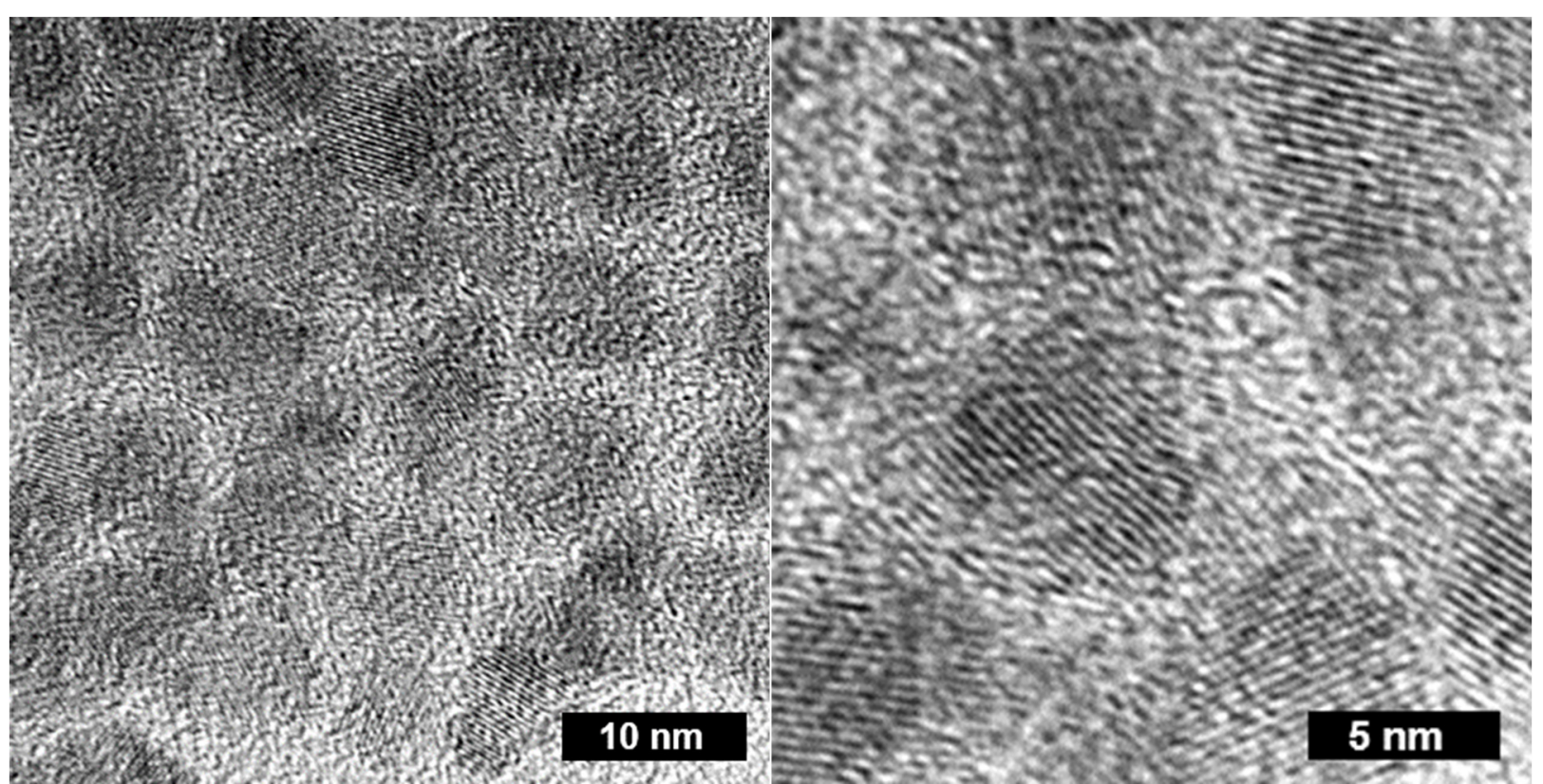

Figure S5. TEM images of OLA. 


\section{FTIR Spectra}

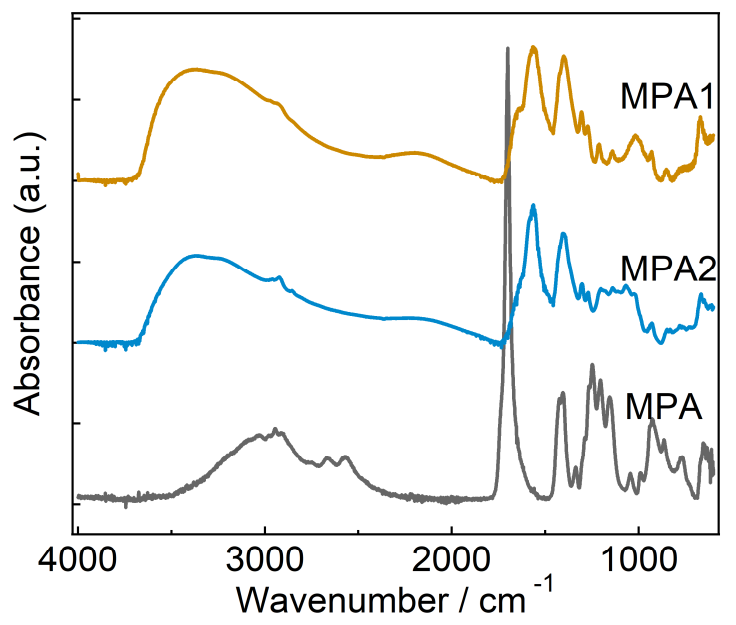

Figure S6. FTIR spectra of MPA and MPA-capped ZnS NCs. The S-H stretching band of MPA at $2567 \mathrm{~cm}^{-1}$ disappeared in MPA-capped ZnS NCs. Moreover, while a $\mathrm{C}=\mathrm{O}$ stretching band was observed at $1700 \mathrm{~cm}^{-1}$ in MPA, the peak was shifted and splint into two peaks at 1401 and $1565 \mathrm{~cm}^{-1}$ in MPA1 and MPA2. These bands are ascribable to the symmetric and antisymmetric stretch modes of $\mathrm{COO}^{-}$. The $\mathrm{S}$ atoms are considered to be coordinated to the $\mathrm{Zn}$ atom at the surface of NCs because the thiolate anion has the stronger affinity to the metal ions than the carboxylate anion. A broad absorption band at around $3270 \mathrm{~cm}^{-1}$ suggests the hydrogen bonding network among carboxylate anions and adsorbed waters at the surface of NCs. ${ }^{4,5}$

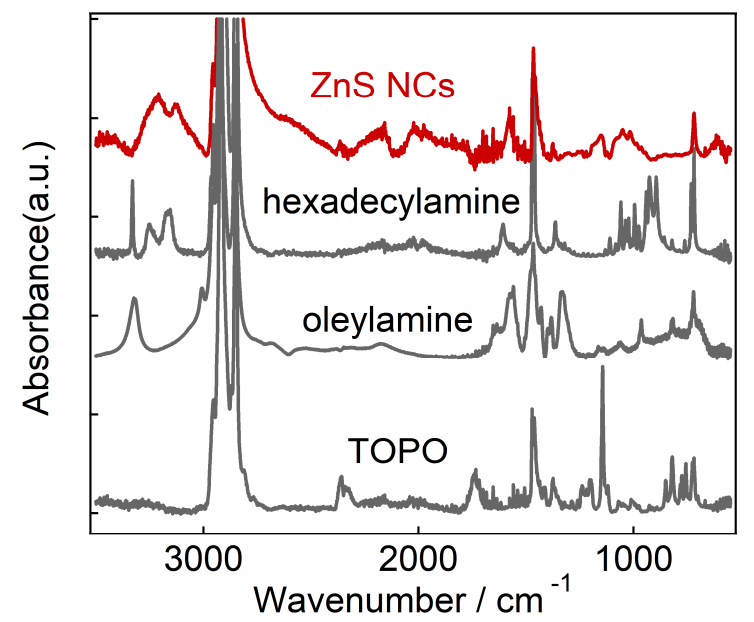

Figure S7. FTIR spectra of hexadecylamine, oleylamine, TOPO, and ZnS NCs synthesized using hexadecylamine, oleylamine, and TOPO as capping reagents (OLA). The $\mathrm{NH}_{2}$-scissoring bands of hexadecylamine and oleylamine at $1600 \mathrm{~cm}^{-1}$ were shifted to the lower wavenumber in capped $\mathrm{ZnS} \mathrm{NCs}$. The $\mathrm{NH}_{2}$ stretching bands of hexadecylamine and oleylamine at $3329 \mathrm{~cm}^{-1}$ were also shifted to the lower wavenumber in the ZnS NCs. It has been reported that the $\mathrm{P}=\mathrm{O}$ stretching band of TOPO at $1142 \mathrm{~cm}^{-1}$ shifts to lower wavenumber when coordinated to surface of NCs. ${ }^{6}$ However, no peaks originating from the $\mathrm{P}=\mathrm{O}$ stretching band were observed in NCs. This suggests that hexadecylamine and oleylamine are the main species for capping reagents of OLA. 


\section{Steady-State Absorption and Emission Spectra}

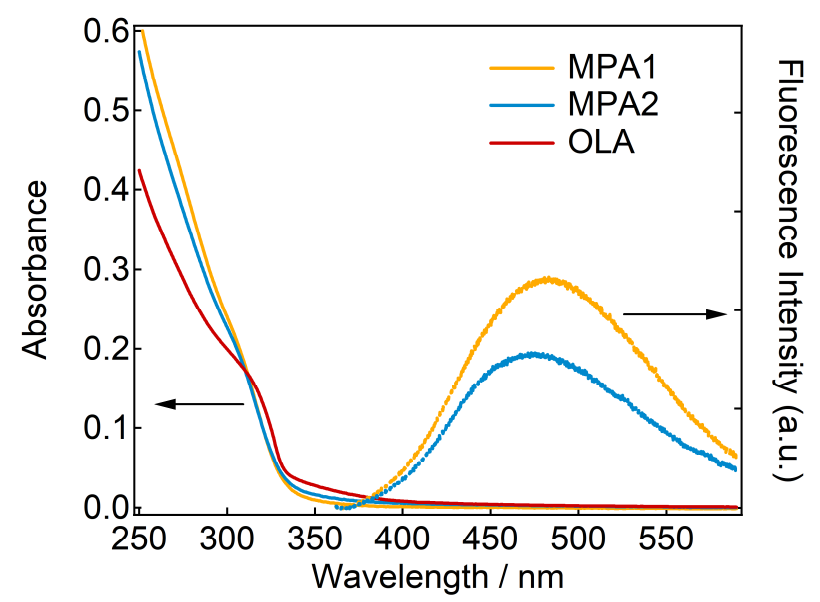

Figure S6. Steady-state absorption spectra and emission spectra of MPA1 and MPA2 in water and absorption spectrum of OLA in chloroform. The excitation wavelength was $317 \mathrm{~nm}$ for the emission measurements. It was difficult to measure the emission spectrum of OLA because of the low emission quantum yield. 


\section{Time Evolutions of the Differential Diffuse Reflectance Spectra of MPA1}

\section{Undried powder of MPA1}

(a)

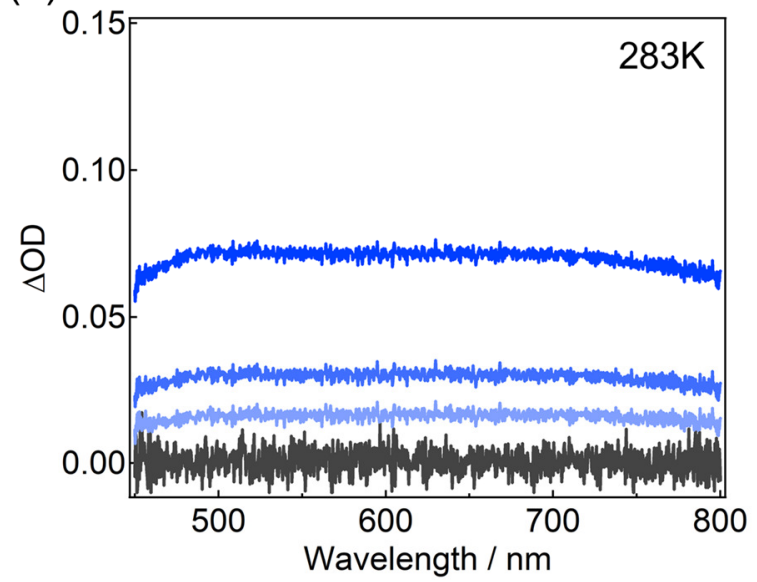

(c)

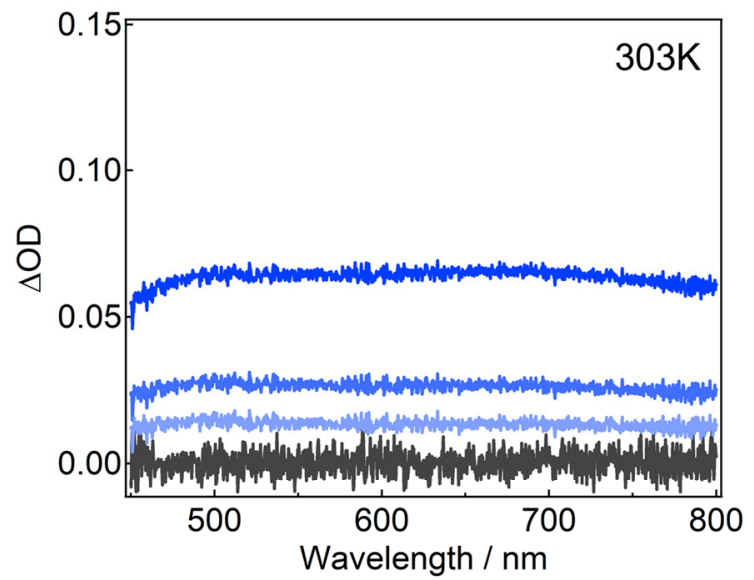

(e)

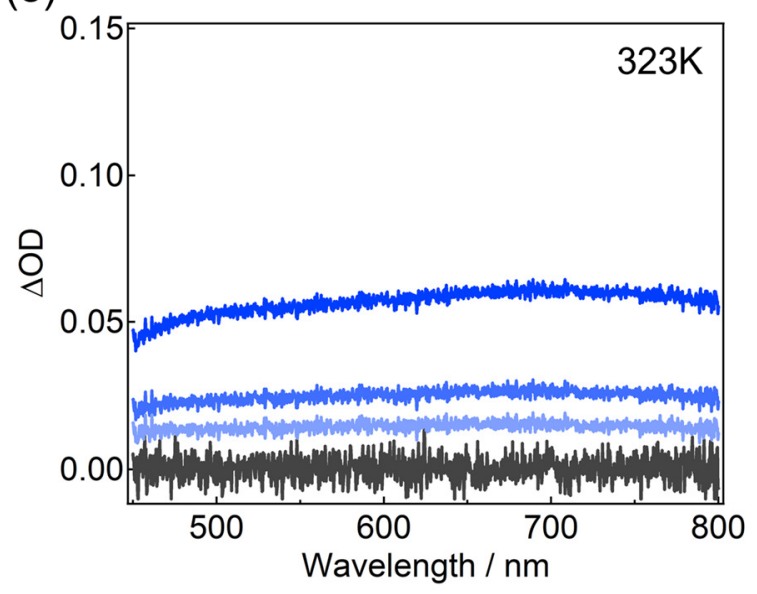

(b)

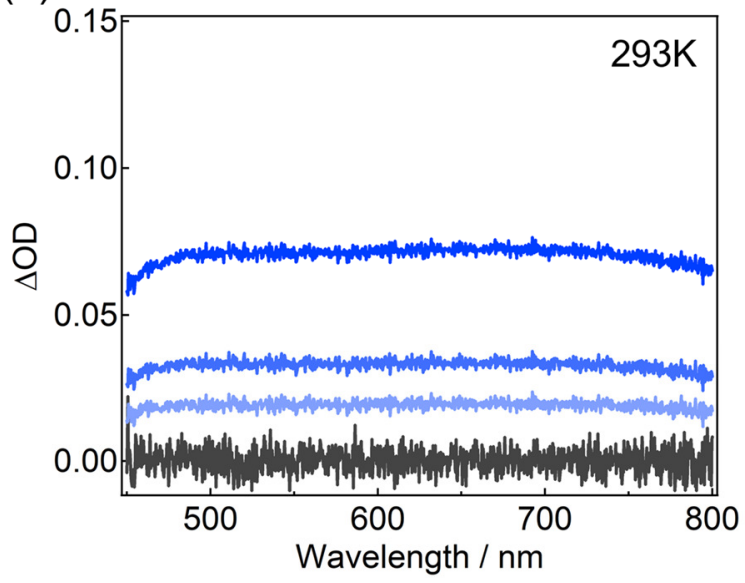

(d)

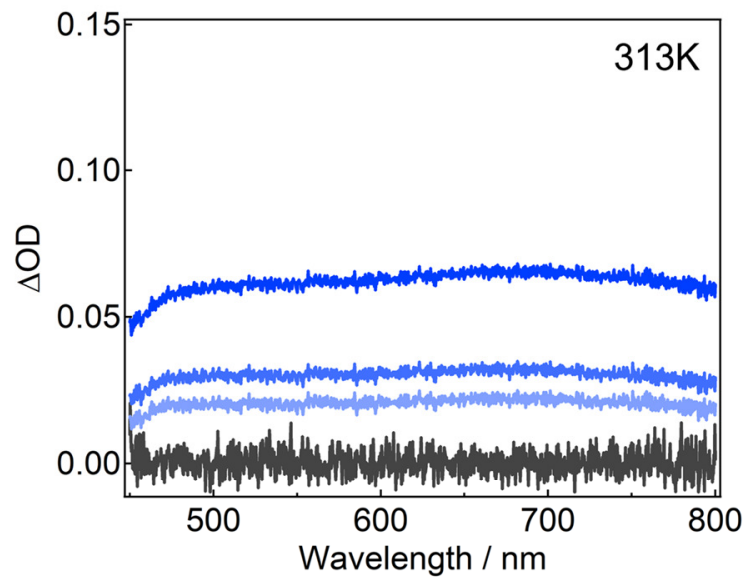

Figure S8. (a)-(e) Time evolutions of the differential diffuse reflectance spectra of the powder of 1\%-Cu-doped ZnS NCs (MPA1) after CW UV light irradiation $\left(365 \mathrm{~nm}, 162 \mathrm{~mW} \mathrm{~cm}^{-2}\right)$ for $10 \mathrm{~s}$ at different temperature under air before the drying (the interval between the spectra is $5 \mathrm{~min}$ ). 
(a)

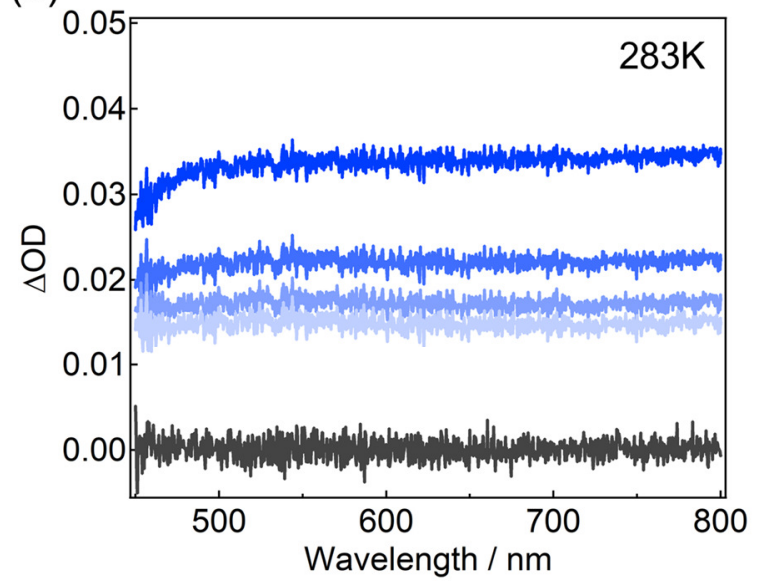

(c)

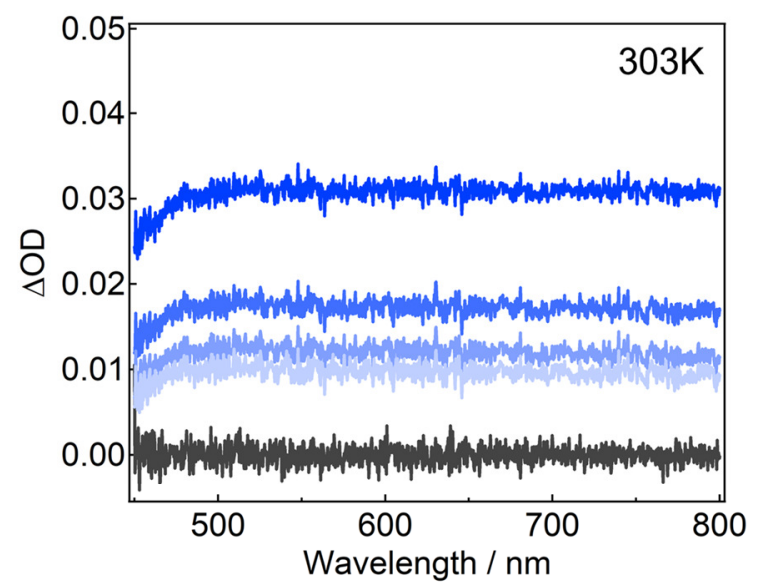

(e)

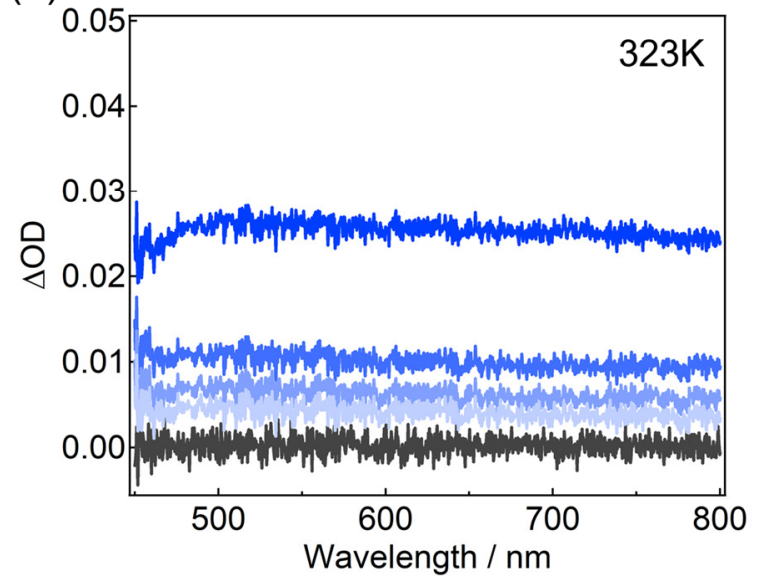

(b)

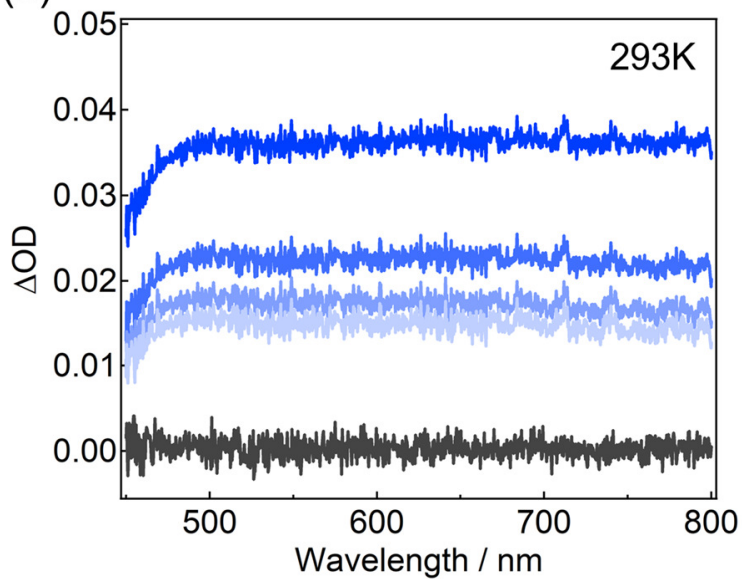

(d)

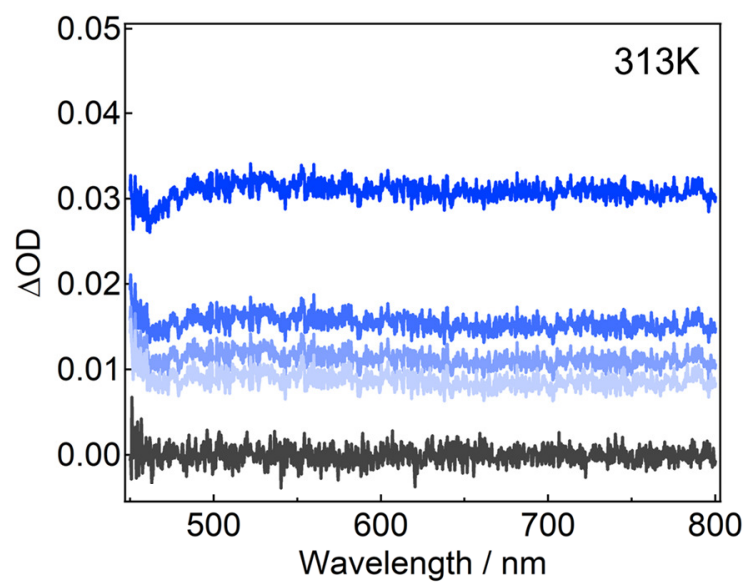

Figure S9. (a)-(e) Time evolutions of the differential diffuse reflectance spectra of the powder of 1\%-Cu-doped ZnS NCs (MPA1) after CW UV light irradiation $\left(365 \mathrm{~nm}, 162 \mathrm{~mW} \mathrm{~cm}^{-2}\right)$ for $10 \mathrm{~s}$ at different temperature under nitrogen after drying (the interval between the spectra is $20 \mathrm{~min}$ ). 


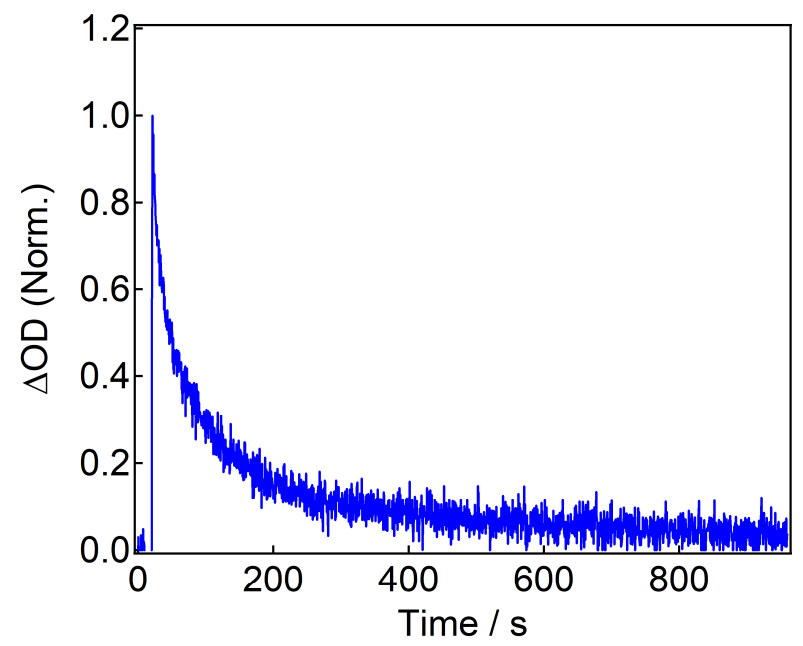

Figure S10. Time evolution of the differential diffuse reflectance probed at $500 \mathrm{~nm}$ of Cu-doped ZnS NCs after UV light irradiation $\left(365 \mathrm{~nm}, 162 \mathrm{~mW} \mathrm{~cm}^{-2}\right)$ for $10 \mathrm{~s}$ under the relative humidity $=50-60 \%$. It clearly shows that the rate of the decoloration reaction is faster than that shown in Figure 2 (the relative humidity was $\sim 20 \%$ ).

\section{Time Evolutions of the Absorption Spectra of a $\mathbf{3 H}$-Naphthopyran Polymer Film.}
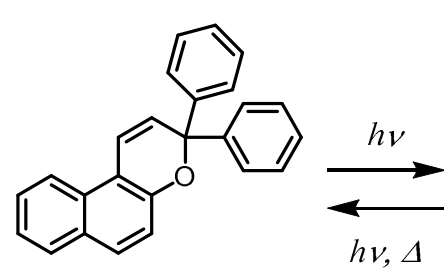<smiles>C=CC(=CC)C(=CC=C1C(=O)C=Cc2ccccc21)c1ccccc1</smiles>

TC

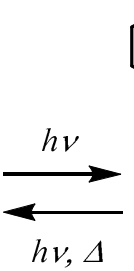

$h v, \Delta$<smiles>O=C1C=Cc2ccccc2/C1=C/C=C(c1ccccc1)c1ccccc1</smiles>

TT

Figure S11. Photochromic reaction scheme of $3 H$-naphthopyran 


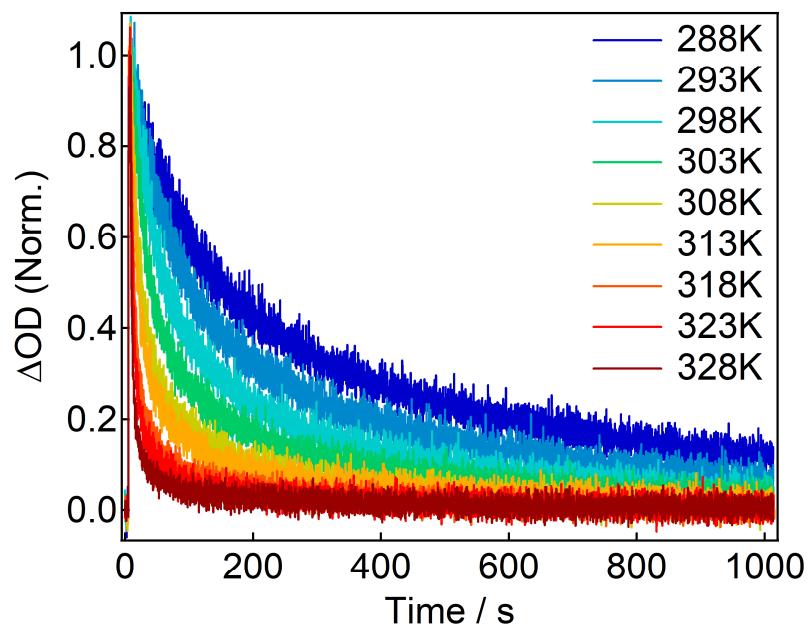

Figure S12. Time evolutions of the differential absorbance probed at $450 \mathrm{~nm}$ of $3 \mathrm{H}$-naphthopyran film after CW UV light irradiation $\left(365 \mathrm{~nm}, 320 \mathrm{~mW} \mathrm{~cm}^{-2}\right.$ ) for $3 \mathrm{~s}$ at different temperature.

(a)

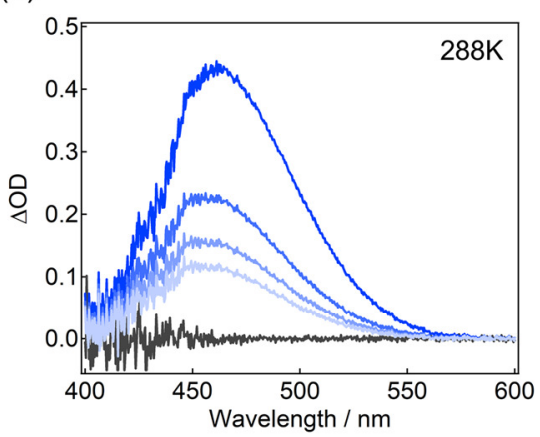

(d)

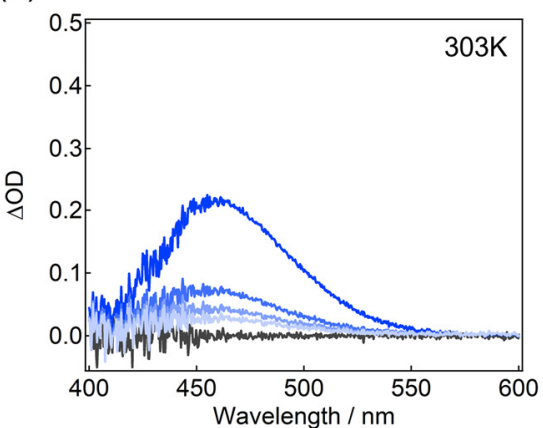

(g)

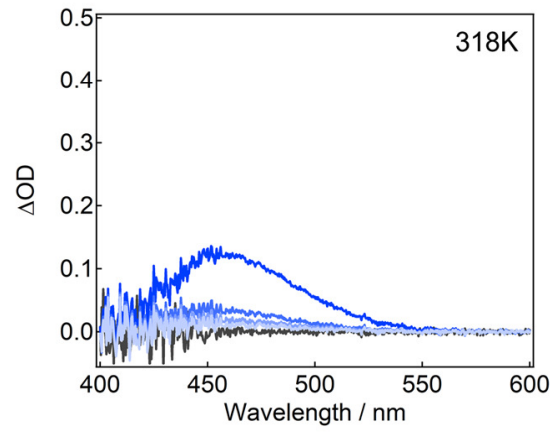

(b)

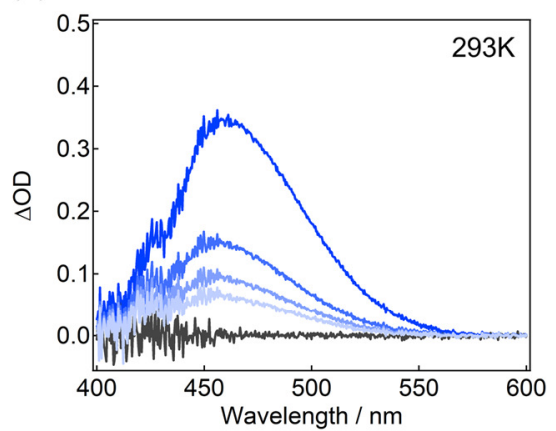

(e)

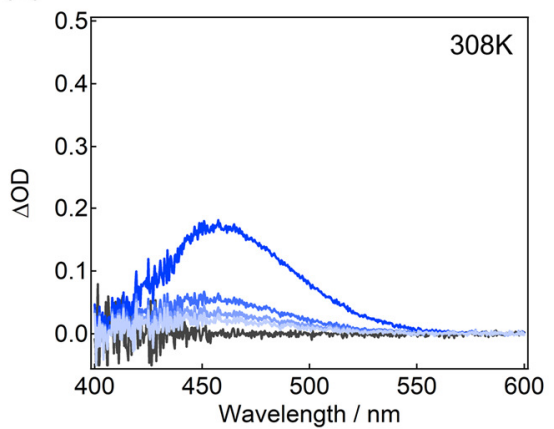

(h)

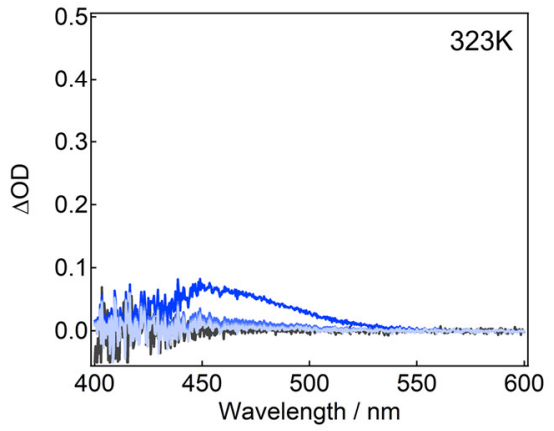

(c)

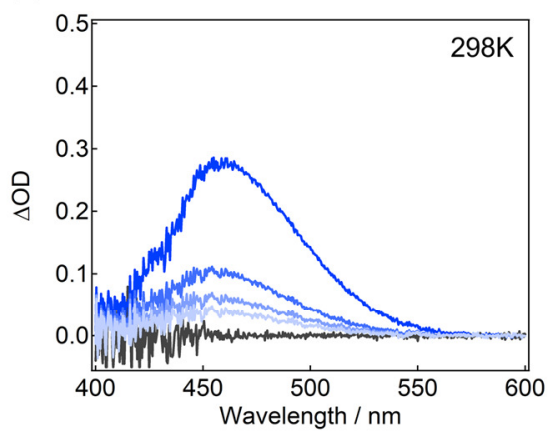

(f)

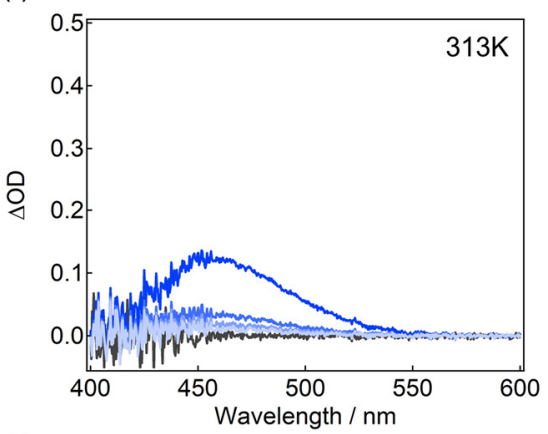

(i)

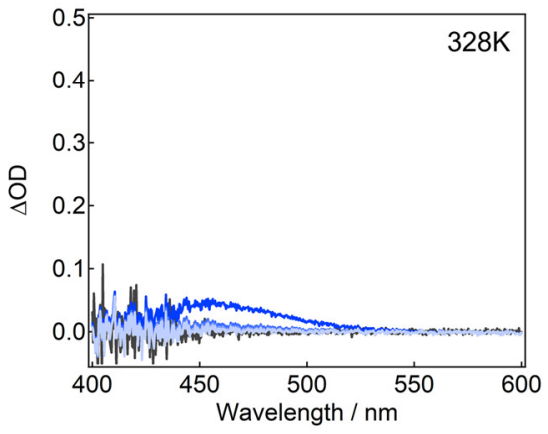

Figure S13. (a)-(i) Time evolutions of the differential absorption spectra of $3 H$-naphthopyran film after CW UV light irradiation ( $365 \mathrm{~nm}, 320 \mathrm{~mW} \mathrm{~cm}^{-2}$ ) for $3 \mathrm{~s}$ at different temperature (the interval between the spectra is $200 \mathrm{~s}$ ). 


\section{FTIR Spectra of MPA1 and MPA2 before and after Drying}

(a)

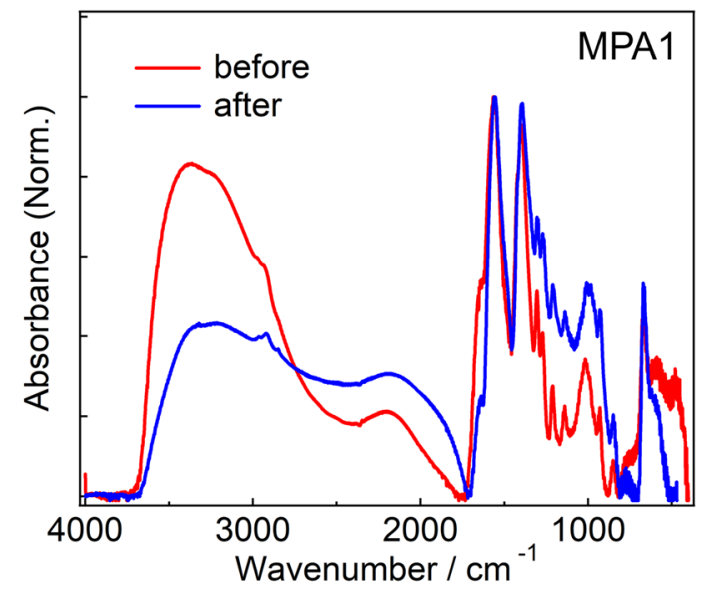

(b)

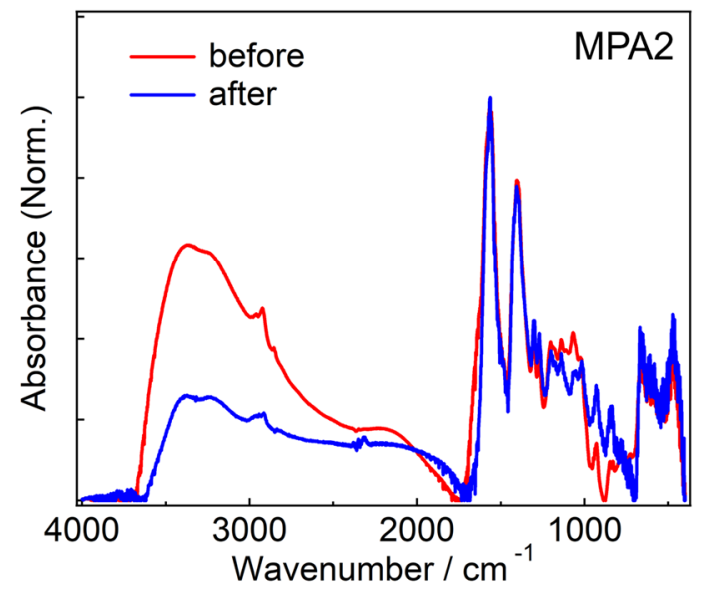

Figure S14. FTIR spectra of (a) MPA1 and (b) MPA2 before and after drying process. After drying, the broad absorption band at around $3300 \mathrm{~cm}^{-1}$ of MPA1 and MPA2 are clearly reduced. This decrease in the signal indicates that the drying process removed significant amounts of the water molecules adsorbed on the NC surface. 


\section{Time Evolutions of the Differential Diffuse Reflectance Spectra of MPA2}

\section{Undried powder of MPA2}

(a)

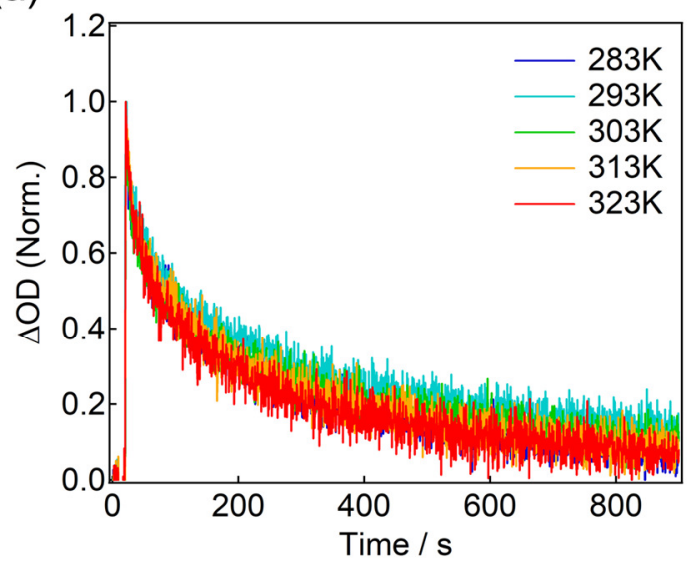

(c)

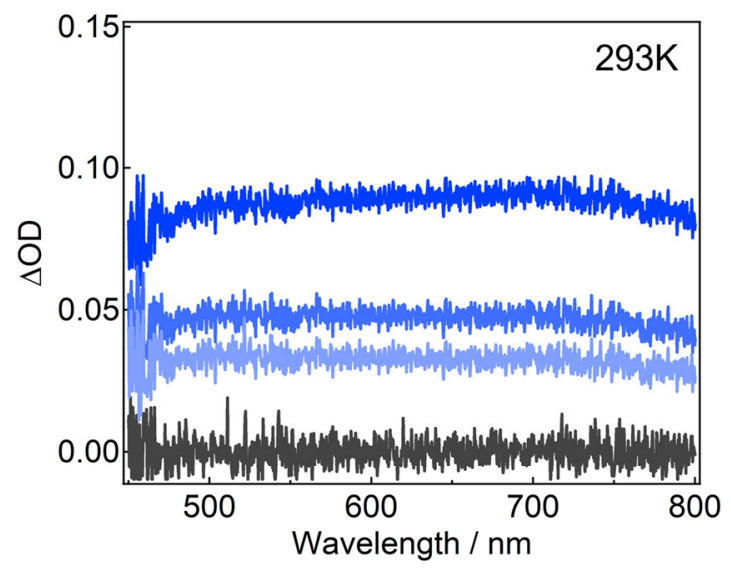

(e)

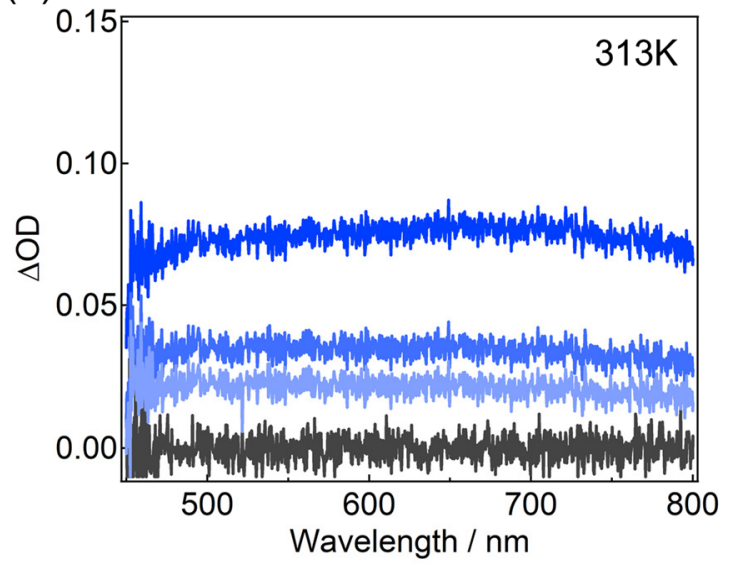

(b)

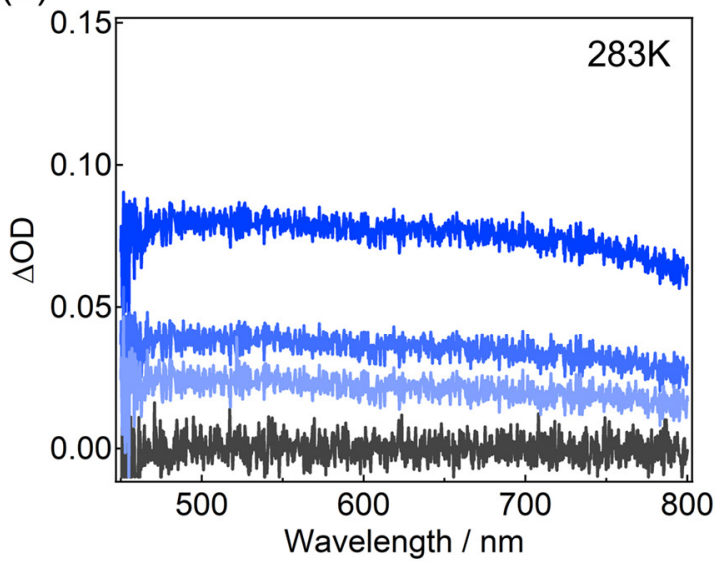

(d)

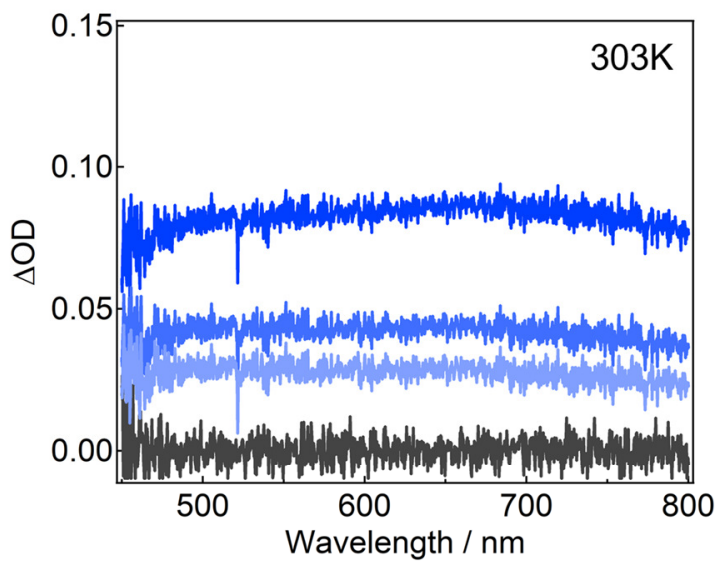

(f)

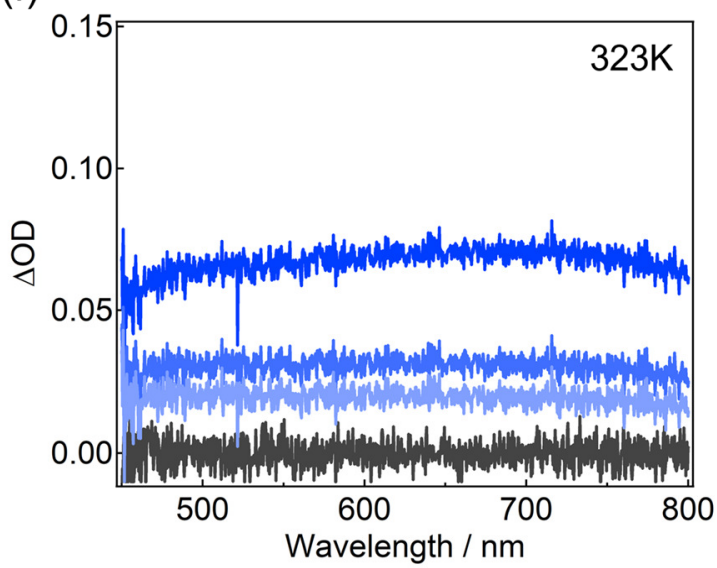

Figure S15. (a) Time evolutions of the differential diffuse reflectance of Cu-doped $\mathrm{ZnS}$ NCs (MPA2) probed at 500 $\mathrm{nm}$ after CW UV light irradiation $\left(365 \mathrm{~nm}, 162 \mathrm{~mW} \mathrm{~cm}^{-2}\right)$ for $10 \mathrm{~s}$ at different temperature under air before drying process. (b)-(f) Time evolutions of the differential diffuse reflectance spectra (the interval between the spectra is 5 $\min$ ). 
(a)

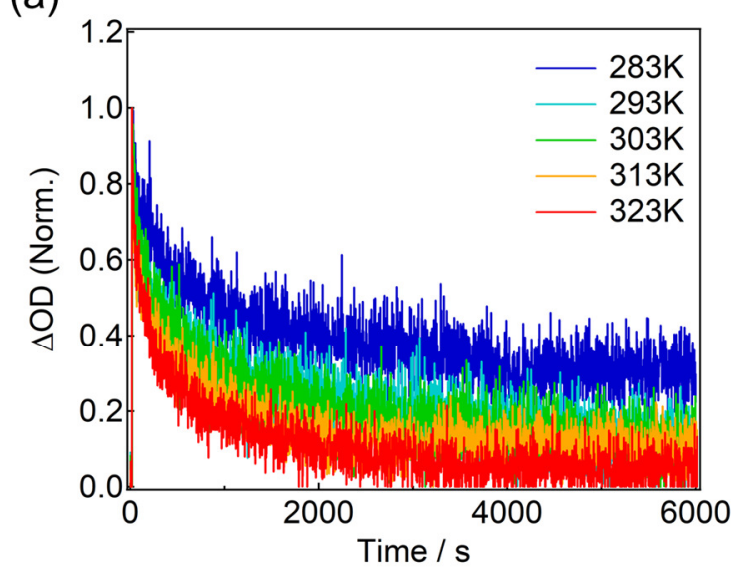

(c)

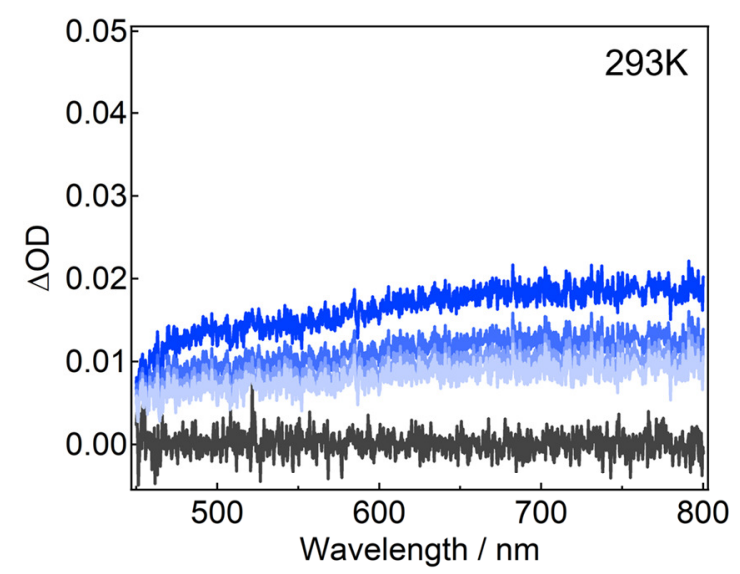

(e)

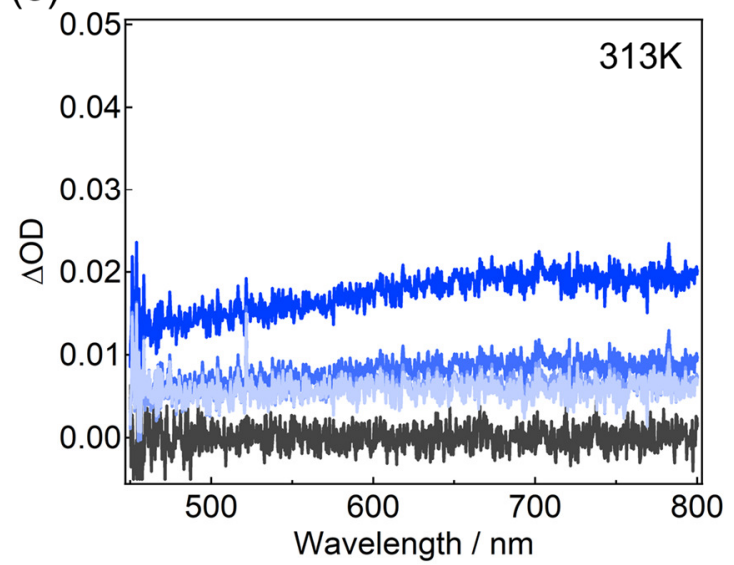

(b)

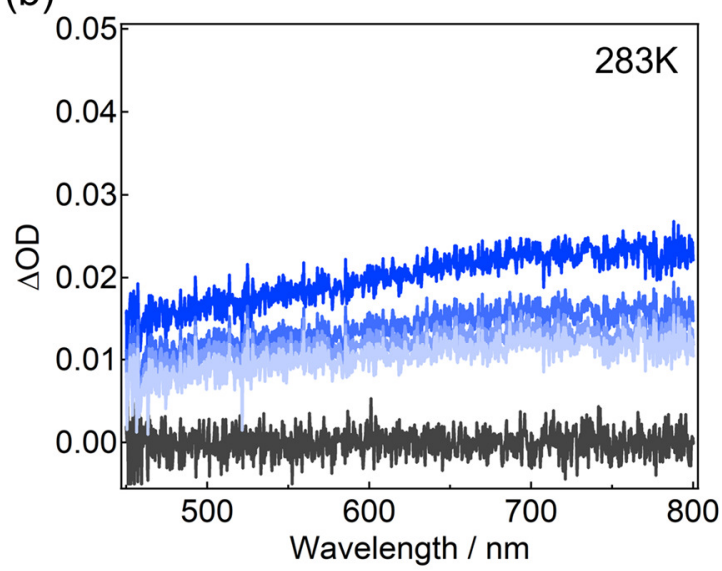

(d)

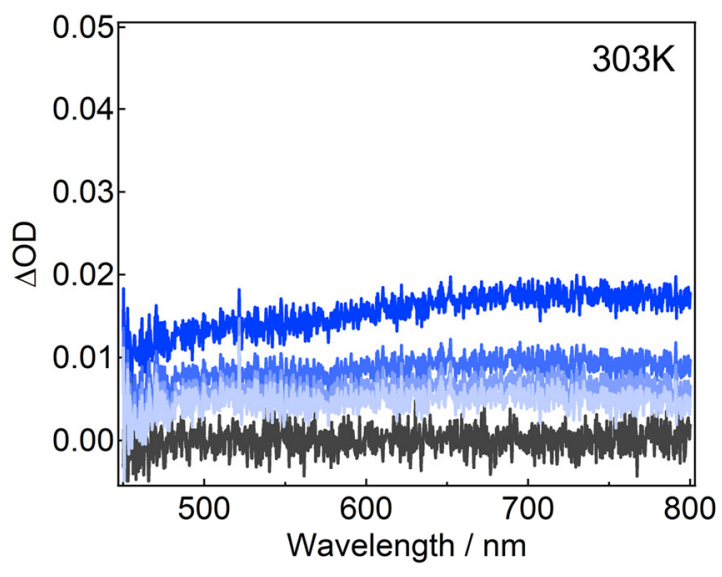

(f)

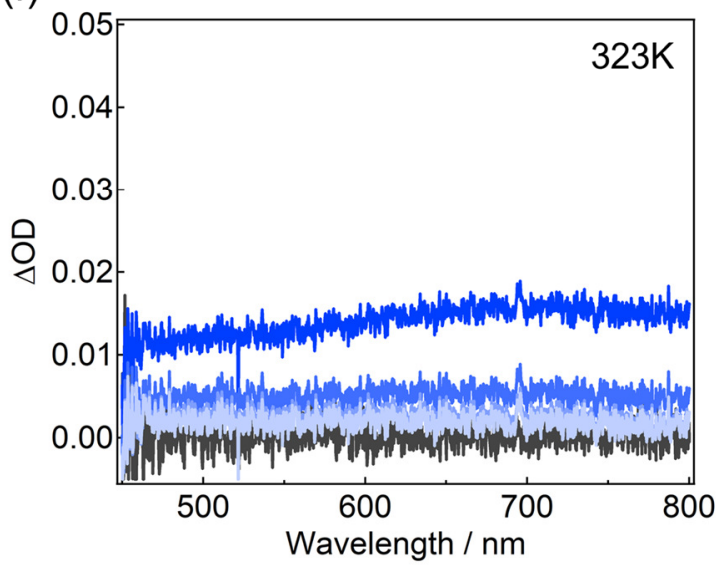

Figure S16. (a) Time evolutions of the differential diffuse reflectance of the powder of 1\%-Cu-doped ZnS NCs (MPA2) at $500 \mathrm{~nm}$ after CW UV light irradiation $\left(365 \mathrm{~nm}, 162 \mathrm{~mW} \mathrm{~cm}^{-2}\right)$ for $10 \mathrm{~s}$ at different temperature under nitrogen after drying process. (b)-(f) Time evolutions of the differential diffuse reflectance spectra (the interval between the spectra is $20 \mathrm{~min}$ ). 


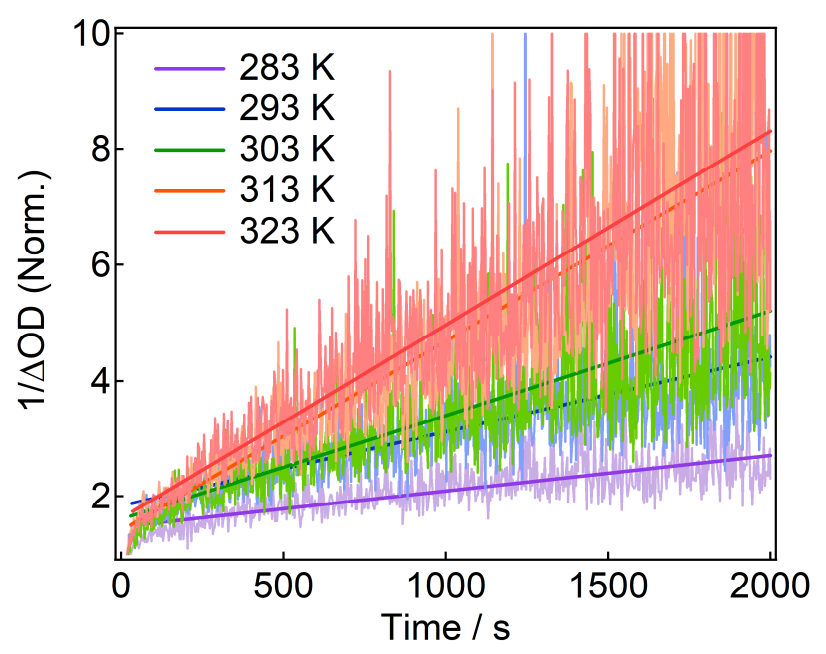

Figure S17. Inverse of the $\triangle \mathrm{OD}$ of the dried powder of MPA2 as a function of time in different temperature. 


\section{Arrhenius Plots}

\section{Powders of MPA1 and MPA2}

(a)

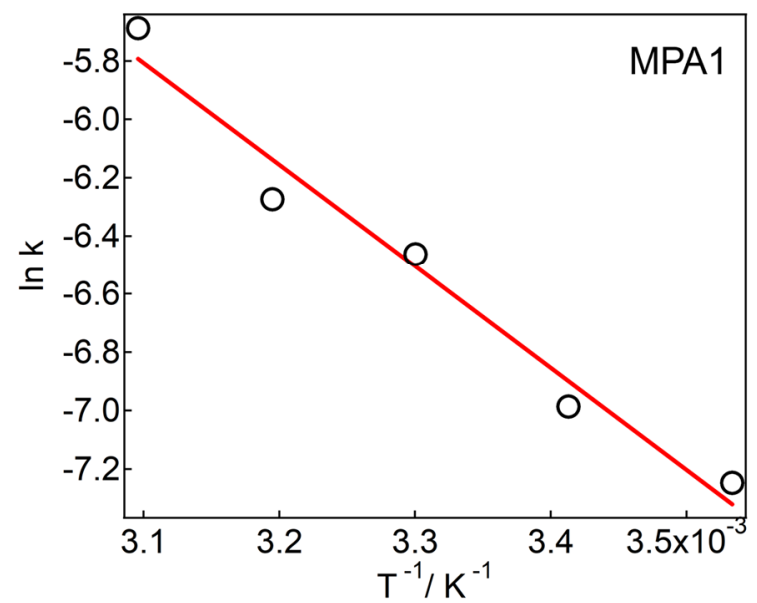

(b)

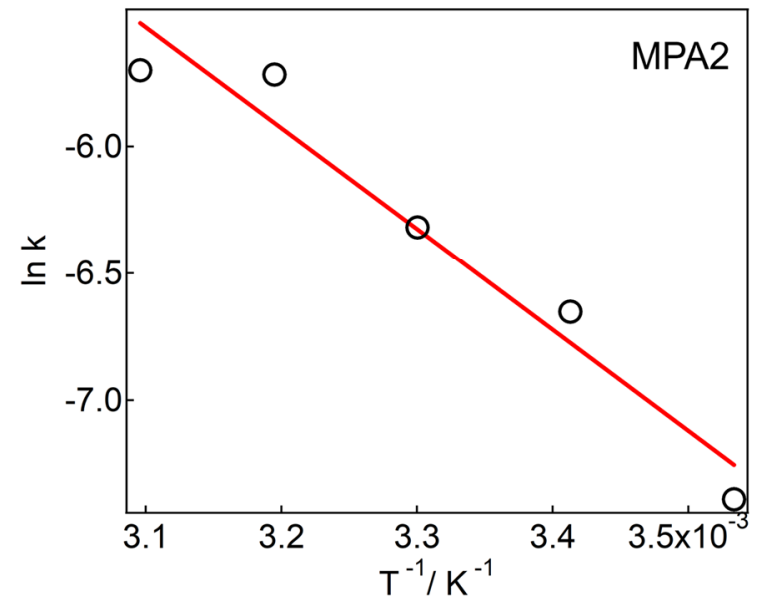

Figure S18. Arrhenius plots of the thermal back reactions of the dried powders of (a) MPA1 and (b) MPA2.

\section{PMMA film of $3 H$-naphthopyran}

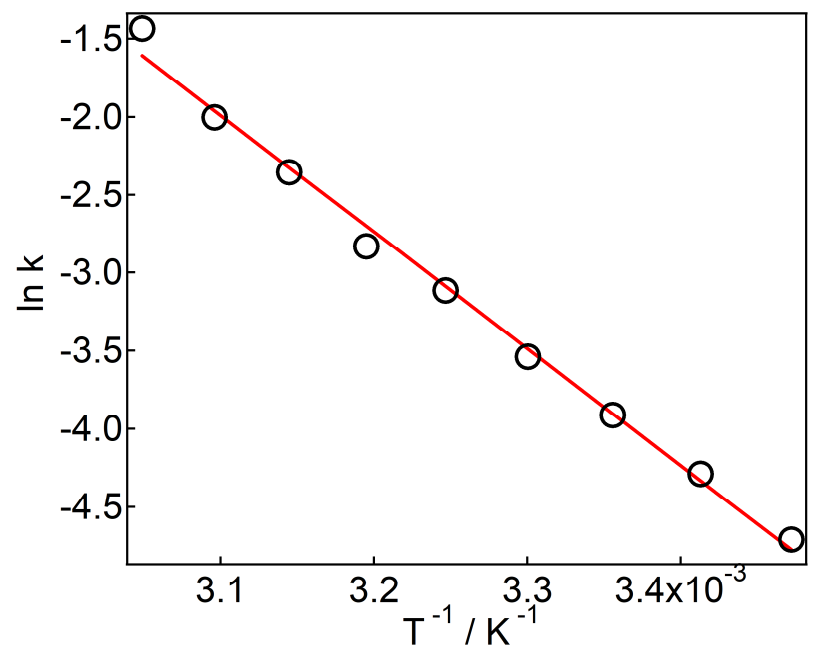

Figure S19. Arrhenius plot of the thermal back reaction of the PMMA film of $3 H$-naphthopyran. The activation energy of the decoloration process of $3 H$-naphthopyran in the polymer film (thermal back reaction of the TC form to the $\mathrm{CF}$ form) was calculated to be $61 \pm 2 \mathrm{~kJ} / \mathrm{mol}$. Since it is difficult to make a simple comparison of activation energies between first-order and second-order reactions, we did not quantitatively compare the results of MPA1, MPA2 and $3 H$-naphthopyran. 


\section{TG-DTA Curves}

(a)

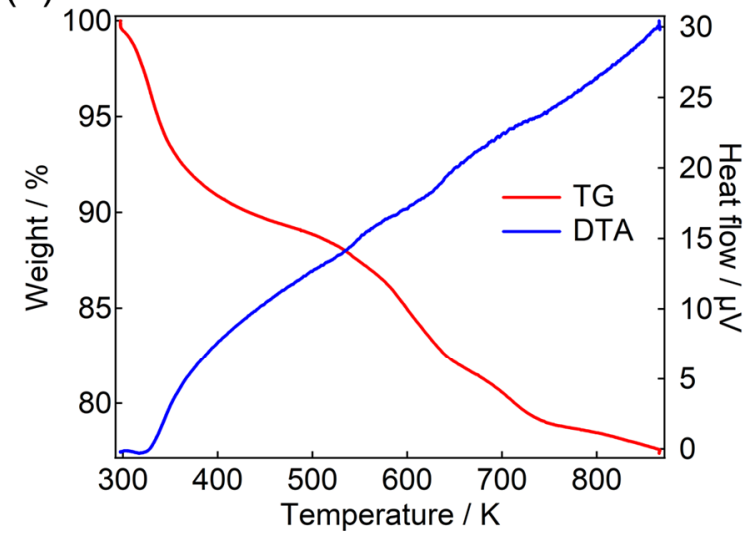

(c)

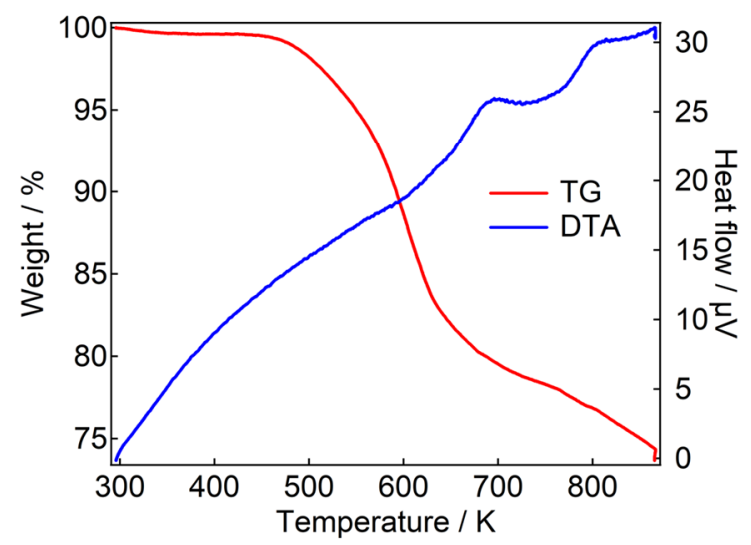

(b)

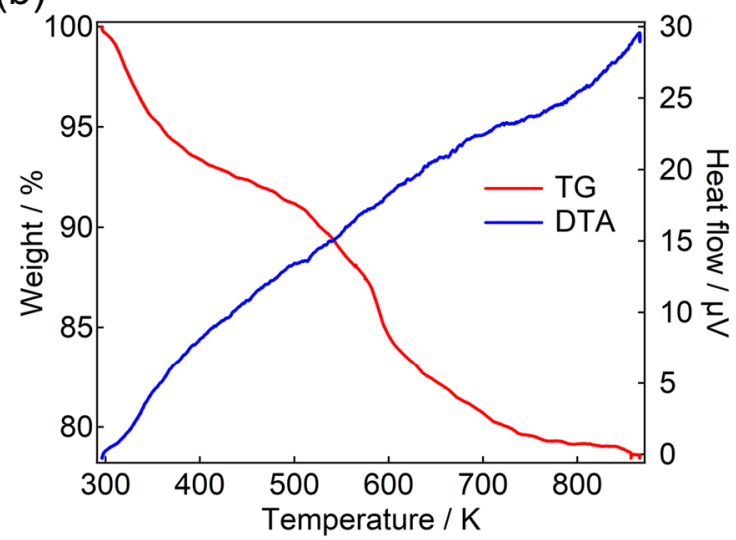

Figure S20. TG and DTA curves of (a) MPA1, (b) MPA2, and (c) OLA under dried $\mathrm{N}_{2}$ with a heating rate of $2.0 \mathrm{~K}$ $\min ^{-1}$. 
(a)

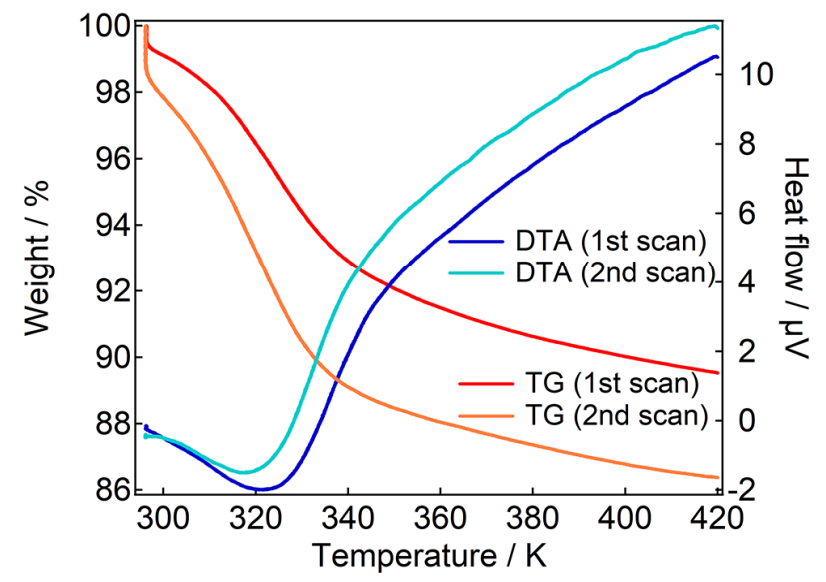

(b)

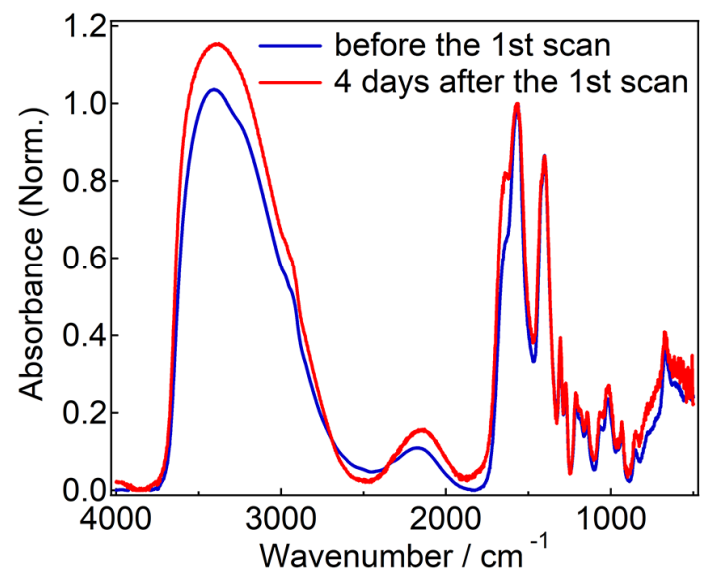

Figure S21. (a) first and second scans of the TG and DTA curves with the same sample of the powder of Cu-doped ZnS NCs. The second measurement was conducted 4 days after storing the sample under air to induce the adsorption of the water molecules again. It shows that both TG and DTA curves are similar in the 1st and 2nd scans, although the amounts of the weight loss and heat flow are different probably because of the different adsorption condition derived from the different humidity. It is noted that the sudden decrease in the weight at $\sim 295 \mathrm{~K}$ is probably due to the artifact of the experimental setup. If the weight loss is originated from the decomposition of organic compounds on the surface of NCs such as MPA, the weight loss of the TG curve of the 2nd scan should be smaller than that of the 1st scan. It suggests that the weight loss in this temperature range mainly reflects the desorption of the adsorbed water molecules with the increase in the temperature. (b) FTIR spectra before the TG-DTA measurement and 4 days after the first TG-DTA measurement of the powder of Cu-doped ZnS NCs. The differences in the region at $~ 3400$ $\mathrm{cm}^{-1}$ and $1650 \mathrm{~cm}^{-1}$ are probably due to the different adsorption condition of water molecules. Therefore, the result also suggests that the decomposition is not a major process. 


\section{Calculation of the Amounts of Water Molecules Adsorbed on the Surface of NCs}

The numbers of water molecules adsorbed on the surface of NCs were estimated from the TG curves shown in Figure 4. To convert the mass $\%$ to mole\%, we estimated the molecular weight of MPA-capped ZnS NCs. The volumes of a NC are calculated to be 29 and $34 \mathrm{~nm}^{3}$ for MPA1 $(D \sim 3.8 \mathrm{~nm})$ and MPA2 $(D \sim 4.0 \mathrm{~nm})$, respectively. The lattice constant of the zincblende $\mathrm{ZnS}$ is $0.54 \mathrm{~nm}$, and the number of $\mathrm{ZnS}$ per unit cell is 4 . Therefore, the volume of the unit cell is $0.16 \mathrm{~nm}^{3}$, and the number of $\mathrm{ZnS}$ per NC are calculated to be 730 and 851 for MPA1 and MPA2, respectively.

To estimate the molecular weight of $\mathrm{ZnS} \mathrm{NC}$, it is important to take the capping reagents into accounts. The surface area of a NC is calculated to be 45 and $50 \mathrm{~nm}^{2}$ for MPA1 and MPA2, respectively. Because the unit cell of the zincblende $\mathrm{ZnS}$ has $2 \mathrm{Zn}$ sites for each surface (the area is $0.29 \mathrm{~nm}^{2}$ ), the number of $\mathrm{Zn}$ sites on the surface of a $\mathrm{NC}$ is calculated to be 311 and 345 for MPA1 and MPA2, respectively. We assumed that all the $\mathrm{Zn}$ sites on the surface of NCs were capped with the thiolate anion of MPA and the S sites were not capped at all. The formula amount of $\mathrm{ZnS}$ is 97.47 and the molecular weight of the carboxylate anion of MPA is 105.14. Thus, the molecular weights of MPA-capped ZnS NC are calculated to be $1.0 \times 10^{5}$ and $1.2 \times 10^{5}$ for MPA1 and MPA2, respectively.

In the TG curves shown in Figure 4, the mass of MPA1 and MPA2 decreased in the range of 293 to $\sim 423 \mathrm{~K}$, while the decrease in the mass of OLA is substantially small. It indicates that the decrease in the mass in this temperature range of MPA-capped $\mathrm{ZnS}$ NCs originates from the desorption of the adsorbed water at the surface of NCs. The decrease in the mass due to the removal of the adsorbed waters ceased at $\sim 423 \mathrm{~K}$. Therefore, we assumed that the mass $\%$ of the adsorbed waters are $10 \%$ and $6 \%$ for MPA1 and MPA2, respectively. The remained mass is ascribable to the mass of NCs (90\% and 94\% for MPA1 and MPA2, respectively). Because the molecular weights of water, MPA1, and MPA2 are 18,1.0 $\times 10^{5}$, and $1.2 \times 10^{5}$, the number of water molecules per NC are estimated to be 640 and 422 for MPA1 and MPA2, respectively.

On the other hand, the numbers of the carboxylate anions per NC are 311 and 345 for MPA1 and MPA2, respectively. These values are smaller than those of the adsorbed waters on the surface of NCs obtained by TG curves (640 and 422 for MPA1 and MPA2). Therefore, the fact that the number of adsorbed water molecules is larger than the estimated number of carboxylate anions indicates that a carboxylate anion captures more than one water molecules probably via hydrogen bonding networks. 


\section{References}

(1) Han, Y.; Hamada, M.; Chang, I. Y.; Hyeon-Deuk, K.; Kobori, Y.; Kobayashi, Y. Fast T-Type Photochromism of Colloidal Cu-Doped ZnS Nanocrystals. J. Am. Chem. Soc. 2021, 143, 2239-2249.

(2) Srivastava, B. B.; Jana, S.; Pradhan, N. Doping Cu in Semiconductor Nanocrystals: Some Old and Some New Physical Insights. J. Am. Chem. Soc. 2011, 133, 1007-1015.

(3) Joo, J.; Na, H. B.; Yu, T.; Yu, J. H.; Kim, Y. W.; Wu, F.; Zhang, J. Z.; Hyeon, T.; Generalized and Facile Synthesis of Semiconducting Metal Sulfide Nanocrystals. J. Am. Chem. Soc., 2003, 125, 11100-11105.

(4) Vo, N. T.; Ngo, H. D.; Vu, D. L.; Duong, A. P.; Lam, Q. V. Conjugation of E. coli O157:H7 Antibody to CdSe/ZnS Quantum Dots. J. Nanomater. 2015, 265315.

(5) Lee, J. W.; Hwang, C. S. White Light Emission from a Colloidal Mixture Containing ZnS Based Nanocrystals: ZnS, ZnS:Cu and ZnS:Mn. Bull. Korean Chem. Soc. 2014, 35, 189-196.

(6) Onwudiwe, D. C.; Hrubaru, M.; Ebenso, E. E. Synthesis, Structural and Optical Properties of TOPO and HDA Capped Cadmium Sulphide Nanocrystals, and the Effect of Capping Ligand Concentration. J. Nanomater., 2015, 143632. 